\title{
Seroepidemiological detection and Culture Utilization for Diagnosis of Carrier Horses and Donkeys with Strangles
}

\author{
Hasanain Abid Alhseen Jaafar Al-Gharban \\ College of Veterinary Medicine, Wasit University \\ Email: hghirban@uowasit.edu.iq
}

\begin{abstract}
This study was aimed for detection of carrier equines with strangles disease through identification of anti-Streptococcus equi antibodies in blood sera of apparently healthy horses and donkeys that inhabitant in different regions belonging to three Iraqi provinces. For this purpose, an overall of 462 equine animals (308 horses and 154 donkeys) were submitted for examining by using of indirect-ELISA that revealed on $22.29 \%$ total positive infections, comprised from $29.87 \%$ seropositive horses and $7.14 \%$ seropositive donkeys. In addition, the culture results of nasopharyngeal swabs samples that obtained, randomly, from 30 horses, seropositively, were revealed on $86.76 \%$ positive samples.

In horses, the seropositive results in Baghdad, Al-Qadisiyah and Wasit provinces were $28.13 \%, 30.27 \%$ and $30.37 \%$, respectively; while in donkeys; they were $9.41 \%$ and $4.35 \%$ in Al-Qadisiyah and Wasit provinces, respectively. The seroprevalence in worker and races horses were $30.96 \%$ and $18.52 \%$ of, respectively, while in age groups, they were $47.54 \%$ and $25.51 \%$ in of $\leq 3$ years and $>3$ years groups, respectively. Also, the seropositive results were $28.68 \%$ in males and $30.81 \%$ in females; whereas, they were $33.49 \%$ of seropositive horses with a history of respiratory signs and $21.88 \%$ without it.
\end{abstract}

Keywords: Strangles, Carrier, Seroepidemiological, Culture, Diagnosis, Horses, Donkeys 
الكثف المصلي الويائي وإتخدام الزرع لتثخيص الخيول والحمير الحاملة لااء الخناق

حسنين عبد الحسين جعفر الغربان

كلية الطب البيطري ، جامعة واسط

\section{الخلاصة}

هدفت الدراسة الحالية الى تحديد الحيوانات الخيلية الحاملة لداء الخناق من خلال كثف الاجسام المضادة للمكورات السبحية الخيلية في مصول دم الخيول والحمير السليمة ظاهريا التي تستوطن في مناطق مختلفة

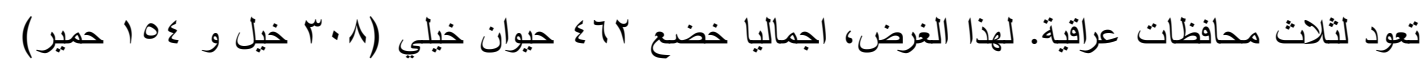

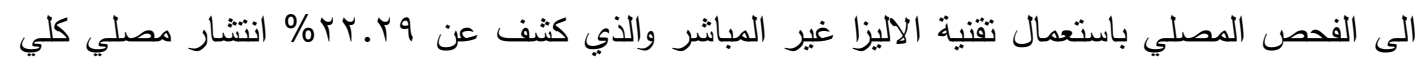

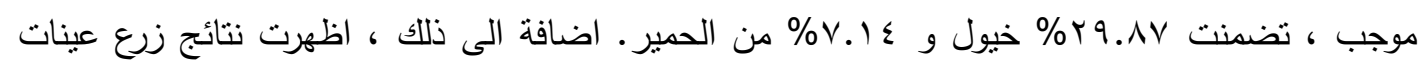

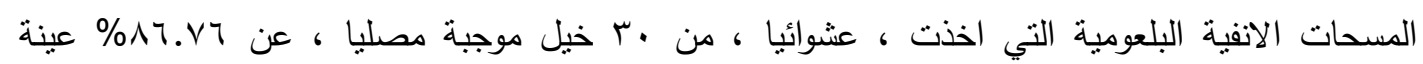

موجبة.

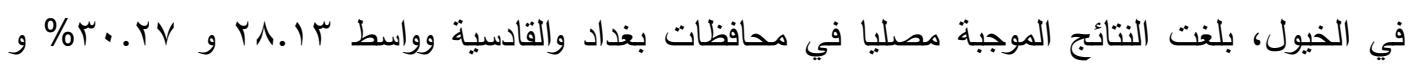

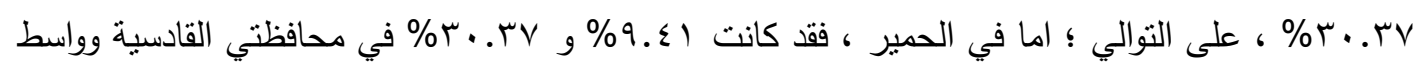

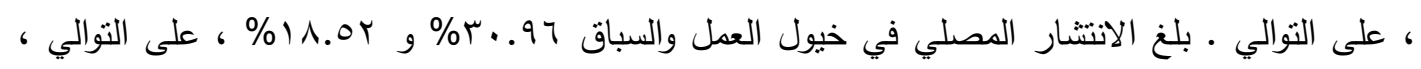

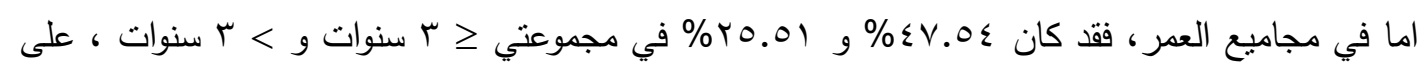

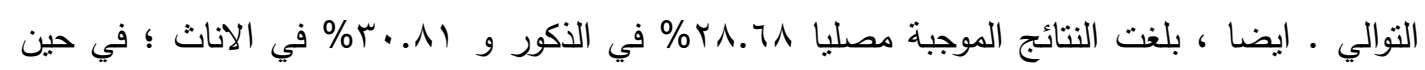

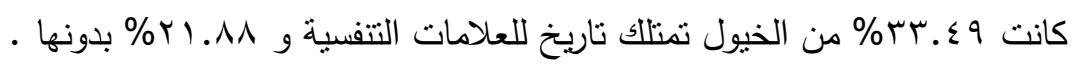

الكلمات المفتاحية : داء الخناق ، حاملة ، مصلي وبائي ، زرع ، تشخيص ، خيول ، حمير 


\section{Introduction}

Strangles is a contagious and infectious disease of upper respiratory tract in horses, donkeys and mules of all ages, caused by Streptococcus equi subsp. equi (S. equi) (1).Worldwide, it is considered as one of the most frequently diagnosed disease in most countries, which occurs with high morbidity and low mortality rates, causing an economic impact due to veterinarian expenses and the need to restrain animals from their activities (2). Although, the transmission can be occur by direct or indirect contact with clinically diseased animals, the recovering and subclinical cases is represented the main important source for infection to susceptible equines (3). Mainly, the acute infections are characterized by high fever, an abscessation of lymph nodes in head and neck, particularly submandibular and retropharyngeal lymph nodes, dysphagia and mucopurulent nasal discharge (4). Nonetheless, the lack of clinical signs exhibited by persistently infected carriers emphasizes the need to implement effective quarantine or testing procedures for their identification and treatment before they come into contact with an existing herd (5). Although, the isolation of organisms by culture still remains the gold standard for diagnosis of acute infections, the absence of bacterial sheds during the persistence phase suggesting the possibility of quantification of specific antibody response (6). Recently, ELISA can be used to detect asymptomatic carriers especially in nonvaccinated animals, as well diagnosing of bastard strangles and immune mediated complications such as purpura haemorrhagica and streptococcal myositis $(7,8)$. The goals of present study were to detect the seroprevalence of specific antibodies against strangles in horses and donkeys of some regions in Baghdad, Al-Qadisiyah and Wasit provinces by using of an indirect ELISA, and estimation the association of positive results in horses with some epidemiological risk factors that included the region, type of work, age, sex as well as a history of respiratory signs.

\section{Materials and methods}

\section{Data and samples collection}

From different areas related to Baghdad, Al-Qadisisyah and Wasit provinces, and during the period of February/2015 to October /2016, a totally of 462 nonvaccinated equines (308 horses and 154 donkeys) were selected randomly for this study. From each one, about $6 \mathrm{ml}$ of blood samples was drained from jugular vein 
by using of a disposable syringe, evacuated in EDTA anticoagulant tubes and centrifuged at $3000 \mathrm{rpm} / 15$ minutes for serum obtaining. The serum samples were saved in numbered $1 \mathrm{ml}$ eppendorf safe-lock tubes that kept at $-20^{\circ} \mathrm{C}$ until is used (9). Also, the required data related to the region, type (Races or workers), age ( $\leq 1$ year and $>1$ year), sex (males and females) and a history of respiratory signs, were reported as epidemiological risk factors.

\section{Serological assay}

The indirect-ELISA (IDvet-USA), based on detection of SeM surface protein, was used in this study for screening of specific IgG-antibodies against $S$. equi. According to manufacturer instructions, all samples and controls sera were diluted, incubated and, finally, measured at $\mathrm{OD}_{450 \mathrm{~nm}}$ by using of a microplate photometer ELISA-reader (BioTek-USA). The test validation and results interpretation of samples and controls (positive and negative) have been performed in dependence on manufacturer guidelines.

\section{Nasopharyngeal swabs}

In order to confirm the carrier infection by culture, a totally of 30 seropositive horses were selected randomly and submitted for naopharyngeal swabs. The samples were transported in cooled inoculated containers with ice, transported to the lab, and submitted for culturing onto blood agar media as described by (10). The beta hemolytic colonies were considered as positive samples for guttural pouch carriers.

\section{Statistical analysis}

All data were arranged, classified and tabled by using of a computerized Microsoft Office Excel (2007), and analyzed by using of the descriptive statistic and Chisquare test $\left(X^{2}\right)$ in IBM/SPSS program (v.23). The significant differences $(P \unlhd 0.05)$ were used to assess the prevalence of seropositive equines and to compare between them. Also, the association of positive results with some epidemiological risk factors was estimated (11). 


\section{Results}

As shown in (Table 1), a totally of 462 equine animals (308 horses and 154 donkeys) were examined by using of indirect-ELISA that revealed on 103/462 (22.29\%) overall seropositive equines, comprised of 92/308 (29.87\%) and 11/154 (7.14\%) horses and donkeys, respectively. A high significant difference $(\mathrm{P} \leq 0.05)$ was reported in seropositive prevalence between horses and donkeys.

Table (1): Seropositive results of 462 equine animals by indirect-ELISA

\begin{tabular}{|c|c|c|c|c|}
\hline \multicolumn{2}{|c|}{ Species } & Total No. & Seropositives & Seronegatives \\
\hline 1 & Horse & 308 & $92(29.87 \%)^{\mathrm{a}}$ & 216 \\
\hline 2 & Donkey & 154 & $11(7.14 \%)^{\mathrm{b}}$ & 143 \\
\hline \multicolumn{2}{|c|}{ Total } & 462 & $103(22.29 \%)$ & 359 \\
\hline
\end{tabular}

Variation in small letters, vertically, referred to a significant difference at $\mathbf{P} \leq \mathbf{0 . 0 5}$

The results of culturing nasopharyngeal swabs of 30 seropositive horses were revealed on $26 / 30(86.67 \%)$ positive swab samples and 4/30 (13.33\%) negative samples (Fig. 1).

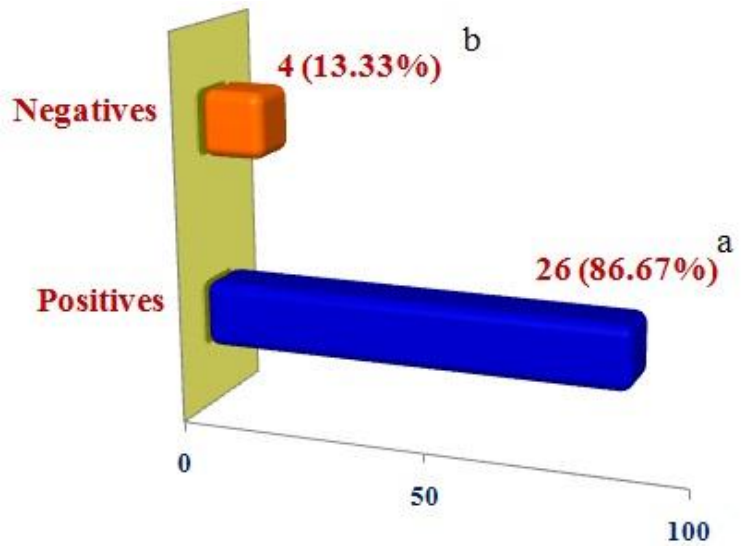

Figure (1): Results of nasopharyngeal swabculture

In (Table 2): According to horses residence factor, the study's results of horses and donkeys were reported that in Baghdad, Al-Qadisiyah and Wasit provinces, the seropositive prevalence was 18/64 (28.13\%), 41/135 (30.37\%) and 3/69 (4.35\%), and $33 / 109(30.27 \%)$ and $8 / 85(9.41 \%)$, respectively. 
Table (2): Seropositive results in according to residence factor

\begin{tabular}{|c|c|c|c|c|c|}
\hline \multicolumn{2}{|c|}{ Residence } & \multicolumn{2}{c|}{ Horses } & \multicolumn{2}{c|}{ Donkeys } \\
\cline { 3 - 6 } & & No. & Seropositivity & No. & Seropositivity \\
\hline 1 & Baghdad & 64 & $18(28.13 \%)^{\mathrm{b}}$ & - & - \\
\hline 2 & Al-Qadisiyah & 109 & $33(30.27 \%)^{\mathrm{b}}$ & 85 & $8(9.41 \%)^{\mathrm{a}}$ \\
\hline 3 & Wasit & 135 & $41(30.37 \%)^{\mathrm{b}}$ & 69 & $3(4.35 \%)^{\mathrm{b}}$ \\
\hline \multicolumn{2}{|c|}{ Total } & 308 & 92 & 154 & 11 \\
\hline
\end{tabular}

Variation in small letters, vertically, referred to a significant difference at $\mathbf{P} \leq \mathbf{0 . 0 5}$

In regarding to work's type factor, the study were exhibited on 5/27 (18.52\%) and 87/281 (30.96\%) seropositive races and worker horses, respectively, (Fig. 2). Whereas in age factor, the study horses were involved 29/61 (47.54\%) and 63/247 (25.51\%) seropositive horses in $\leq 3$ years and $>3$ years group, respectively, (Fig. $3)$.

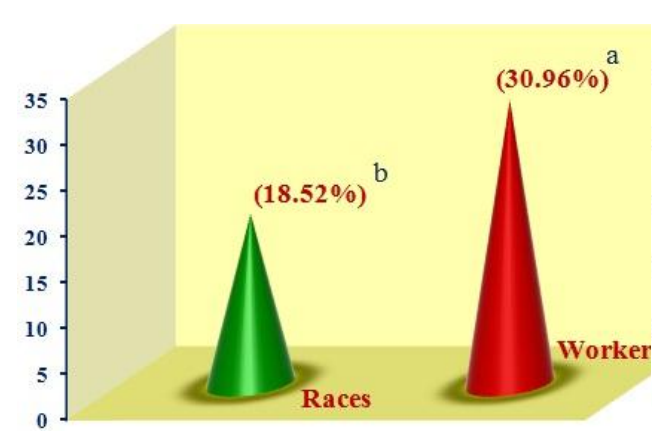

Figure (2): Seropositive horses in according to

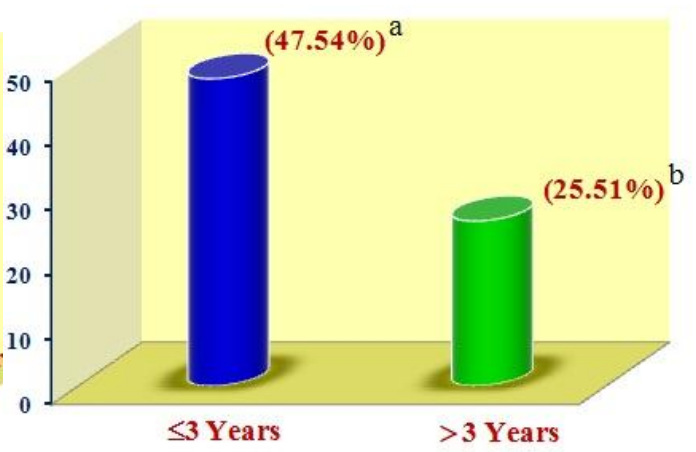

Figure (3): Seropositive horses in according to age factor 
In according to horse's sex factor, the positive seroprevalence were 39/136 (28.68\%) males and 53/172 (30.81\%) females (Fig.4). Also, the results showed that $71 / 212(33.49 \%)$ and $21 / 96(12.88 \%)$ of seropositive horses were with a history of respiratory signs and without it, respectively, (Fig.5).

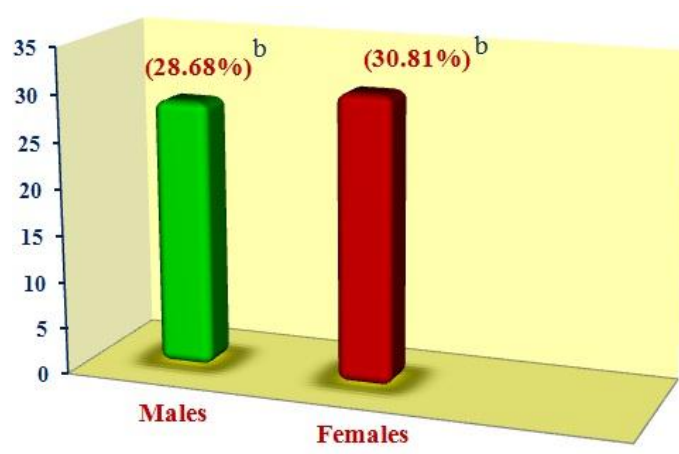

Figure (4): Seropositive horses in according to sex factor

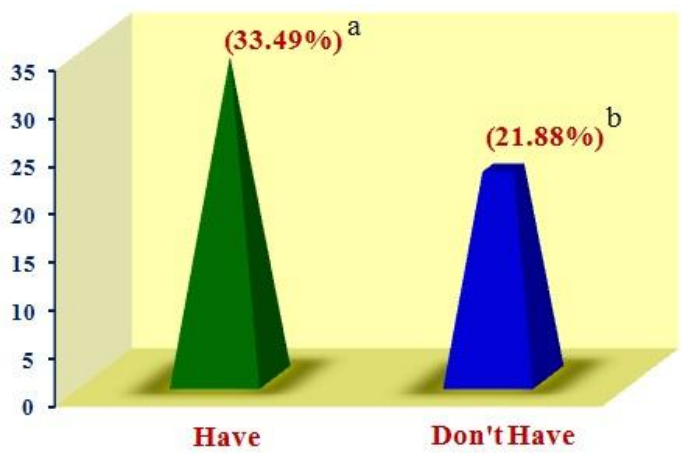

Figure (5): Seropositive horses in according to a history of respiratory cions fartor

\section{Discussion}

Carrier horses with strangles as defined by the Animal Health Trust (AHT) are meaning "they infected with $S$. equi, not show any clinical signs and act as a source of infection for other susceptible individuals, which be determined, only, if they have an evidence of an antibody response" (12). In this study, though the total seropositive prevalence of strangles was $22.29 \%$, it was indicated that the horses (29.87\%) were more susceptible for $S$. equi infection than donkeys (7.14\%) (Table1). Although, the true causes were fully unknown and required for further investigation, the low prevalence in donkeys could be attributed to the low number of obtained samples, less-exposure for infection sources, no imported donkeys and natural resistance. However, the positive results of horses were lower than those reported, locally, by $(13,14)$.

Globally, the studies that pertained to the prevalence or incidence rates of strangles and the role of some risk factors in development of strangles are very rare. Nevertheless, the prevalence of disease in horses, as reported by previous disease, 
was 37.5\% in Iran (15), 28\% in Saudi Arabia (16), $45.2 \%$ in Pakistan (17), 18.4\% in Canada (18), and 13\% in British (19). In Iraq, strangles is considered as one of most important endemic diseases that affected equine animals at all seasons of year as a result of continual importation of races horses from different worldwide origins, persistence of carrier animals that seemed to be healthy (12), lack of actual bio-security and an absence of active vaccinations schemes, especially, for worker horses.

The current codes of practice on equine diseases published by the Horserace Betting Levy Board (HBLB) suggested that" No convalescent horse or in contact can be considered free from infection until three negative nasopharyngeal swabs and the horse has been tested by guttural pouch endoscopic examination and lavage" (5). Though, the detection of asymptomatic carriers by using of classical screening methods as bacteriological culture or endoscopic assessment of guttural pouches is difficult because of these methods are very cost, impractical for routine screening of large numbers of horses at low risk of being infected with strangles, low sensitive and non-specific, as well as, the intermittent shedding of bacteria from carrier equines $(20,21)$.

As shown in (Fig.1), the results of indirect-ELISA were confirmed through culturing of the nasopharyngeal swabs that obtained from seropositive horses and revealed on $86.67 \%$ positive samples. Hence, the current available serological ELISA that developed by the AHT has been allowed to detect the specific IgGantibodies for two novel $S$. equi specific antigens (19) Also, this assay has the ability for revealing of recent exposure to $S$. equi with a high sensitivity (92\%) and specificity (91\%), and detecting of asymptomatic carriers with $90.9 \% 82.6 \%$ of sensitivity and specificity, respectively (22).

In regarding to residency factor, although the prevalence of seropositive horses didn't show any significant differences $(\mathrm{P} \leq 0.05)$ between the studied provinces, it's more prevalent in donkeys of Al-Qadisiyah than Wasit (Table 2). As well as, some factors were discussed in, only, horses due to rarity of data that related to donkeys. In a factor of work's type (Fig.2), the worker horses reported a high seroprevalence of $S$. equi when compared to races horses, and this might be attributed to genetic variation (2 $)$, high exercise, decrease attention to therapy and absence of vaccination program, poor hygienic conditions $(2 \xi)$, waning immunity and frequent exposure to different pathogens (3). 
In regarding to age factor (Fig.3), the study reported that the younger horses with $\leq$ 3 years were appeared to be having a high seropositive prevalence than older $>3$ years horses, and these results were in agreement with those detected by $(11 ; 13)$. Typically, strangles can be affected horses at all age categories but the yearlings are most severely affected with longer duration of clinical signs $(4,17)$. Whereas, the older equines with residual immunity have limited susceptibility or develop a mild form of strangles and shedding the pathogen with production of a sever disease in more susceptible or younger animals $\left(2^{\circ}\right)$.

Among horses of both sex groups, the study reported that females $(30.81 \%)$ have more seropositive prevalence than males $(28.68 \%)$, but without significant differences (Fig.4), which could be attributed to that both sexes were at the same risk for infection.

The prevalence of strangles in a history of presence respiratory signs group was showed to be more than a group of absence it (Fig.5). Despite a severity of clinical signs during acute phase of disease, the vast majority of equines could be recovered from strangles over a period of weeks, and the exposure of horse to strangles might be occurred without knowledge of its owner (2ఛ). In addition, many worldwide outbreaks were thought to be happened but with atypical clinical signs that attributed to the difference in $S$. equi strains $\left.(r), 2^{\vee}\right)$. However, respiratory signs in horses could be attributed to several pathogenic and non-pathogenic (allergic) that occurred, mostly, due to the poor management, and the ability of $S$. equi to establish persistent infection is critical to inter-epizootic transmission, recurrence of strangles and a high incidence of infection around the world $\left(2^{\wedge}, 2^{9}\right)$.

In conclusion, this was the first study concerned with identification of carrier equines with strangles by using of indirect-ELISA in apparently healthy horses and donkeys, and confirmation of seropositive horses result by culture. Also, the study evaluated the role of seropositive carriers among the different regions of three Iraqi provinces, ages and sexes. Hence, the efficient identification and treatment of carriers is very important for prevention and/or eradication of this disease. 


\section{References}

1. Arias Gutiérrez, MP. (2013). Strangles: the most prevalent infectious respiratory disease in horses worldwide. CES Medicina Veterinariay Zootecnia, 8(1), 143159.

2. Islam SMS., Purnat TD., Phuong NTA., Mwingira U., Schacht K., Fröschl, G. (2014). Non-Communicable Diseases (NCDs) in developing countries: a symposium report. Globalization and health, 10(1), 81 .

3. Sweeney CR., Timoney JF., Newton JR., and Hines, MT. (2005). Streptococcus equi infections in horses: guidelines for treatment, control, and prevention of strangles. Journal of Veterinary Internal Medicine, 19(1), 123-134.

4. Taylor SD., and Wilson, WD. (2006). Streptococcus equi subsp. equi (Strangles) infection. Clinical Techniques in Equine Practice, 5(3), 211-217.

5. Waller, AS. (2014). New perspectives for the diagnosis, control, treatment, and prevention of strangles in horses. Veterinary Clinics of North America: Equine Practice, 30(3), 591-607.

6. Waller AS., and Jolley, KA. (2007). Getting a grip on strangles: recent progress towards improved diagnostics and vaccines. The Veterinary Journal, 173(3), 492-501.

7. Mallicote, M. (2015). Update on Streptococcus equi subsp. equi infections. Veterinary Clinics of North America: Equine Practice, 31(1), $27-41$.

8. Libardoni F., Vielmo A., Farias L., Matter LB., Pötter L., Spilki FR., and de Vargas, AC. (2013). Diversity of seM in Streptococcus equi subsp. equi isolated from strangles outbreaks. Veterinary microbiology, 162(2), 663-669.

9. Moraes CM., Vargas AP., Nogueira CE., Leite FP., and Gil-Turnes, C. (2009). Immunogenicity and cross reactivity indices of Streptococcus equi subsp. equi strains isolated from cases of Strangles and commercial vaccines. Ciência Rural, 39(5), 1459-1464.

10. Newton JR., Verheyen K., Talbot NC., Timoney JF., Wood JL., Lakhani KH., and Chanter, N. (2000). Control of strangles outbreaks by isolation of guttural pouch carriers identified using PCR and culture of Streptococcus equi. Equine veterinary journal, 32 (6), 515-526.

11. Petrie A., and Watson, P. (2006). Statistics for Veterinary and Animal Science, Second Edition. Ames: Blackwell Publishing, Pp: 24-112.

12. Weese, J. S. (2014). Infection control and biosecurity in equine disease control. Equine veterinary journal, 46(6), 654-660. 
13. Al-Judi AH., Saleh MA, and Hameed, RM. (2011). Incidence of strangles in Baghdad. Al-Anbar Journal of Veterinary Sciences, 4 (1), 31-33.

14. Alwan, JA. (2014). Used of Real -Time PCR technique for detection of Streptococcus equi from horses infected by strangles in AL-Diwanyia Provence, Iraq. International Journal of Advanced Research, 2 (4), 208-213.

15. Mohammadi A., Borujeni MP., Gharibi D., and Mashhadi, AG. (2016). A serological survey on strangles disease in horses of some areas in Khuzestan province by ELISA. Journal of Veterinary Research, 71(4).

16. Al-Ghamdi, GM. (2012). Serology study of Streptococcus equi in Saudi Arabia. Veterinary Research, 5(5), 107-109.

17. Ijaz M., Khan MS., Dourani AZ., Saleem MH., Chaudhry AS., Ali MM., Mehmood K., and Shahzad, W. (2012). Prevalence and Biochemical Studies of Strangles (Streptococcus equi) Affected horses in Pakistan. The Journal of Animal \& Plant Sciences, 22(2), 295-299.

18. Clark C., Greenwood S., Boison JO., Chirino-Trejo M., and Dowling, PM. (2008). Bacterial isolates from equine infections in western Canada (19982003). Canadian Veterinary Journal, 49(2), 153.

19. Knowles EJ., Mair TS., Butcher N., Waller AS., and Wood, JL. (2010). Use of a novel serological test for exposure to Streptococcus equi subspecies equi in hospitalised horses. The Veterinary record, 166(10), 294.

20. Verheyen K., Newton JR., Talbot NC., De Brauwere MN., and Chanter, N. (2000). Elimination of guttural pouch infection and inflammation in asymptomatic carriers of Streptococcus equi. Equine veterinary journal, 32(6), 527-532.

21. Laus F., Preziuso S., Spaterna A., Beribe F., Tesei B., and Cuteri, V. (2007). Clinical and epidemiological investigation of chronic upper respiratory diseases caused by beta-haemolytic Streptococci in horses. Comparative immunology, microbiology and infectious diseases, 30(4), 247-260.

22. Robinson C., Steward KF., Potts N., Barker C., Hammond TA., Pierce K., and Waller, AS. (2013). Combining two serological assays optimises sensitivity and specificity for the identification of Streptococcus equi subsp. equi exposure. The Veterinary Journal, 197(2), 188-191.

23. Kelly C., Bugg M., Robinson C., Mitchell Z., Davis-Poynter N., Newton JR., and Waller, AS. (2006). Sequence variation of the SeM gene of Streptococcus equi allows discrimination of the source of strangles outbreaks. Journal of clinical microbiology, 44(2), 480-486. 
24. Ebrahim F., Feyera T., and Abera, B. (2016). Major animal health constraints of market oriented livestock in Kersa Woreda, Southwest Ethiopia. Adv. Anim. Vet. Sci, 4(2), 92-98.

25. Brazil, T. (2005). Strangles in the horse: management and complications. Practice, 27(338), e347.

26. Boyle, A. (2011). Streptococcus equi subspecies equi infection (strangles) in horses. Compend. Contin. Educ. Vet, 33, E1-7.

27. Newton JR., Wood JL., and Chanter, N. (2003). A case control study of factors and infections associated with clinically apparent respiratory disease in UK Thoroughbred racehorses. Preventive veterinary medicine, 60(1), 107-132.

28. Couëtil LL., Rosenthal FS., DeNicola DB., and Chilcoat, CD. (2001). Clinical signs, evaluation of bronchoalveolar lavage fluid, and assessment of pulmonary function in horses with inflammatory respiratory disease. American journal of veterinary research, 62(4), 538-546.

29. Mb M., and Thiongane, Y. (2012). Note on epizootic infection for the chronic upper respiratory diseases caused by beta-hemolytic Streptoccocus equi observed on indigenous horses on Dakar's region in Senegal. African Journal of Microbiology Research, 6(6), 1109-1112. 